\title{
Learning Leadership Abroad: An Overview of a Short-Term Leadership-Focused Study Abroad Program in Italy
}

\author{
David M. Rosch, Ph.D. \\ Assistant ProfessorAgricultural Leadership \\ University of Illinois at Urbana-Champaign \\ Urbana, IL \\ dmrosch@illinois.edu \\ Paige Haber-Curran, Ph.D. \\ Assistant Professor \\ Student Affairs in Higher Education \\ Texas State University \\ San Marcos, TX \\ ph31@txstate.edu
}

\begin{abstract}
We provide a brief description of a leadership-oriented short-term (nine days) study abroad program offered in May 2012. The program centered in Rome, Italy, combined classroom curricula with field experiences in the city as well as in Bologna and Florence. Initial quantitative and qualitative assessment suggested the program helped student development both in their leadership practices as well as their personal development.
\end{abstract}

\section{Introduction}

Effective leadership in an increasingly global society requires understanding and interacting effectively within other cultures (Earnest, 2003; Hofstede \& Hofstede, 2004). In this era of globalization the most important challenge facing leaders is how to work across cultural differences and cultural boundaries to achieve goals and accomplish change (Wibbeke, 2009). Further, there is a need for future leaders to better understand global issues and develop the skills to become globally literate (Moore, Boyd, Rosser, \& Elbert, 2009). A focus on global leadership education is essential "as the world becomes increasingly interdependent, complex, uncertain, and dynamic [and] the challenge to understand and operate within that world... become[s] ever more difficult" (Oddou \& Mendenhall, 2008, p. 174).

\section{Global Leadership Education through Study Abroad}

Higher education institutions seek to prepare students to be globally and culturally competent citizens. Further, a central focus of higher education is developing a sense of community within college graduates; study abroad and international experiences provide an opportunity to expand the focus of community to 
include a global dimension (Dalton \& Sullivan, 2008). "Exposing students to the world beyond the local levels of community helps to enlarge their understanding of and commitment to a richer and more layered vision of community" (p. 9). To address these institutional goals and others, colleges and universities implement a variety of study-abroad and international experiences that allow students to expand their learning outside of the traditional classroom (Institute of International Education, [IIE], 2012). Study abroad is an experiential learning opportunity focusing on diversity, culture, and global issues; these programs are identified as high-impact educational practice that helps facilitate meaningful student learning (Kuh, 2008).

A traditional classroom environment limits the potential for the development of global skills and intercultural competence often sought in study abroad programs (Montgomery \& Arensdorf, 2012). Although traditional classroom pedagogy, primarily centered on lecturing, can be efficient in transferring content knowledge, it often lacks effectiveness when seeking to "foster the development of process skills" (Duch, Groh, \& Allen, 2001, p. 5). They suggest that with college alumni noting skills such as problem solving skills, interpersonal skills, management skills, and technical writing skills as being more pivotal and useful to their work than technical field-based knowledge, there is a need to look beyond traditional classroom learning environments when facilitating student learning (Duch et al., 2001). Further, with college graduates entering an increasingly global society, there is a need for graduates to "function in a global community" (p. 5). Effective study abroad programs provide opportunities to combine knowledge acquisition with an immersion experience where students engage with, live in, observe, and experience the subjects of their study (Baumgratz, 1995; Robinson, 2005). Immersion in a new culture challenges students' preconceived ideas about the culture and facilitates increased critical thinking skills, openness, and discovery (Montgomery \& Arensdorf, 2012). Research on study abroad programs suggests study abroad participants gain a greater understanding of themselves, of others, and of the larger global society (NAFSA, 2003) as well as increased intercultural competence (Martinez, 2012). The Association of International Educators (NAFSA, 2003) contends "an educational opportunity outside the United States can be among the most valuable tools for preparing a student to participate effectively in an increasingly interconnected international community that demands cross-cultural skills and knowledge" (p. 4).

Recently there has been an increase in study abroad opportunities focused on leadership (see The Journal of Leadership Studies May 2012 issue as an example). This is fitting, particularly as effective leadership learning should include experiential and practical knowledge and capacity-development (Rosch \& Anthony, 2012). Leadership-centered study abroad experiences encourage students to look beyond their previously held worldviews and lenses, challenging and broadening their thinking (Montgomery \& Arensdorf, 2012; Robinson, 2005). Through examining, applying, and engaging with others around concepts of leadership in a different culture, students expand their understanding of diversity, a concept central to modern conceptualizations of leadership (Montgomery \& Arensdorf, 2012; Ostick \& Wall, 2011). Additionally, students have the opportunity to build reciprocal relationships across cultures and gain exposure to the larger global society, pushing and broadening students' understanding of what constitutes leadership for the "greater good" (Robinson, 2005). Further, studying leadership abroad allows students to come to understand varying global perspectives on leadership outside of their country of origin. These goals and outcomes of leadership-focused study abroad programs are central to moving leadership education forward; "anyone who wants to study or to exercise leadership successfully must 
become more educated about the world, about diverse cultures and interests, and about different ways of working with others to influence an increasingly complex, connected, and conflicted system" (Robinson, 2005, p. 82).

The number of short-term (eight weeks or less) study abroad programs has significantly increased over the past decade (Institute of International Education, 2012). These short-term programs are often more conducive to students' academic schedules and degree plans; they also can be less costly for students. Although the research into student learning through short-term study abroad programs is limited, the results show positive outcomes. Qualitative research on students enrolled in short-term study abroad programs (each less than three weeks) suggest the development of cultural content knowledge in addition to intercultural competence, including intercultural awareness, abilities, attitudes, behaviors, knowledge, skills, and values (Martinez, 2012; Scoffham \& Barnes, 2009). A quantitative study examining students' development of global-mindedness showed short-term experiences predicted higher global-mindedness scores compared to students who had not yet studied abroad but who intended to do so (Kehl \& Morris, 2007). Additional literature and research is needed to understand student learning through short-term study abroad programs. The program described here is a short-term study abroad experience focused on student leadership learning and development. Further, initial suggestions of student learning are provided through quantitative and qualitative assessments.

\section{Short-Term Study Abroad Program in Italy}

During the 2011-2012 academic year, faculty in the College of Agriculture, Consumer, and Environmental Sciences at the University of Illinois at Urbana-Champaign partnered with staff at the Swiss School of Management, located in Rome, to allow for a group of 15 undergraduate students to spend nine days studying leadership in Rome, Florence, and Bologna, Italy. The overarching goals of the program were two-fold: (a) study both classic and current Roman leaders and (b) provide American students the opportunity to study leadership from Eurocentric perspective. The specific outcomes for the study abroad course were: (a) review highlights of significant leaders in Roman Republic and Roman Empire, and analyze their leadership style and effects of their decisions, (b) visit relevant historical sites that are related to these leaders, (c) compare and contrast modern Italian businesses in their culture and decision-making with the Roman Empire, (d) connect both the in-class formal curriculum and experiential learning opportunities to students' own leadership development and personal development, and (e) explore parts of Rome and Florence informally.

Classroom time spent at the Swiss school focused on classical Roman leaders such as Julius Caesar, Constantine, and historic Roman Catholic popes as well as modern leaders such as the recent and current CEOs of modern Italian corporations including Salvatore Ferragamo and Ducati Motorcycles. To engage students more experientially, travel was arranged throughout sites within the city of Rome to study the impact of decisions made by the same historic leaders covered within the classroom. For example, a visit to the Coliseum included a tour of the premises along with an explanation of how and why the Catholic Church funded its restoration during the Renaissance. Longer trips were provided for students to Florence to meet with staff at Ferragamo and to Bologna to tour the Ducati Motorcycle factory. Pairing classroom instruction with experiential field trips allowed students to more deeply and intellectually grasp the material covered within the short-course. In addition, during each excursion, students were provided 
unstructured time for them to explore the area on their own. This provided students the opportunity to shed a guided-tour mindset to more autonomously engage with their environment and the culture.

Although the program lasted only nine days, each day and evening was filled with classroom instruction, traveling to various sites, and ample time for discussion and group reflection. In addition, individual reflection papers were turned in to the course instructors four times throughout the experience - before the trip began, soon after it started, near the end, and a week after the trip concluded. The discussions and reflection opportunities were designed for students to make deep meaning of their experience and integrate their learning into their own practice of leadership upon their return.

\section{Potential Effects of International Leadership Experiences}

The study abroad program was designed as an initial foray into providing an international experience for students studying leadership at the University of Illinois at Urbana-Champaign. To that end, faculty conducted both an exploratory quantitative and qualitative assessment of students' leadership and personal development to help better understand the effects of the program.

\section{Quantitative Assessment}

In addition to student satisfaction data, students completed a survey that included the Motivation to Lead scale (MTL) (Chan \& Drasgow, 2001) and Leadership Self-Efficacy scale (Dugan \& Komives, 2007) two weeks prior to participating and again one week after the program concluded. The Motivation to Lead scale consists of three subscales: (a) an Affective-Identity (AI) scale that describes the intensity to which students see themselves as leaders, (b) a Social-Normative (SN) scale that identifies the depth to which students feel responsible to lead their peers, (c) a Non-Calculative (NC) scale that expresses the degree to which students choose not to engage in a cold calculation of individual costs and benefits to leading before choosing to lead. The Leadership Self-Efficacy (LSE) scale determines the degree of confidence students possess in engaging in leadership within a group setting.

A total of 10 students completed both pretest and posttest surveys. Within that group, the mean scores of all MTL subscales, as well as the LSE scale, all increased an average of 0.2 on a 5-point Likert scale. However, given the tiny sample size, even a paired-samples $t$-test conducted to compare pretests to posttests for each subscale would not possess appropriate degrees of statistical power to demonstrate significant results (Cochran, 1977). Cohen's d calculations showed a moderate effect for each subscale and the LSE - ranging from .27 to .47 - but even effect size has been shown to fluctuate significantly by sample size (Slavin \& Smith, 2009). While these results are positive, and reinforce past research suggesting that short-term programs result in measurable growth (Kehl \& Morris, 2007), they should be considered preliminary at best.

\section{Qualitative Assessment}

A brief content analysis of student reflection papers served to highlight the benefits of an abroad experience in leadership studies. Many reflection comments focused on one of three topics - the experience of another culture's leadership practices and values, the pairing of classroom material with on- 
site investigation, and personal development resulting from independently navigating within a new culture.

\section{Immersion within another Culture}

Many students wrote about expanding their thinking through the experience of diversity, a finding echoed in previous research (Martinez, 2012; Ostick \& Wall, 2011). For example, one student wrote about thinking about corporate leadership in a different way after learning about the role of family and family relationships in several leading Italian firms. Another stated that she developed a more nuanced understanding of modern leadership styles after immersing herself deeply in the history of the building of the Roman Empire.

\section{Pairing of Classroom and Field Experiences}

Several students commented on how their learning deepened through the combination of classroom instruction and visiting relevant sites. One student wrote, "The mixture... helped [me] grasp the history conceptually as well as physically." Several students used the phrase, "the big picture" to describe how their understanding of leadership decisions went beyond textbook platitudes to comprehending the systemic forces that led to those decisions only after physically visiting a site.

\section{Personal Development}

Many students discussed how they were expected to navigate, in part, on their own within a community where many did not primarily speak their language. These students often placed their abroad experience as an additional step within the context of "growing up" and becoming ready to attain adulthood, which is a theme evident in non-leadership-focused study abroad experiences as well (NAFSA, 2003). For example, multiple students commented on how they often thought of themselves as "leaders" but were forced to become more follower-like when placed in the unfamiliar environment of a non-Englishspeaking country; learning how to independently navigate such an environment led them to generalize how they could apply such learning to numerous unfamiliar situations in the future.

\section{Conclusion}

Short-term study abroad academic opportunities can create powerful learning experiences for students. Further, short-term study abroad experiences provide a relatively cost-efficient way for students to learn about leadership in a global context (Martinez, 2012). The practice and research on short-term study abroad programs and interest in their application for leadership education are both rising. This article describes a specific case where a short-term learning abroad experience in Italy was implemented at one institution with a focus on leadership education and development outcomes. Initial quantitative and qualitative assessment results have been positive, suggesting that over the course of nine days that students grow in their personal and leadership development. This program could serve as a template for other institutions interested in creating international partnerships for similar programs. Preliminary findings from this leadership study abroad course reflect the importance of providing ample opportunities for students to immerse themselves in the foreign culture - both formally and informally. Additionally, the findings suggest intentionally pairing curricular components with field experiences to help students 
synthesize their leadership learning. As more institutions become interested in leadership-oriented study abroad programs, additional examination is necessary on student learning from the experiences and on the best ways to structure curriculum and design the study abroad experience to optimize student learning and growth.

\section{References}

Baumgratz, G. (1995). Language, culture, and global competence. European Journal of Education, 30(4), 437-448.

Chan, K., \& Drasgow, F. (2001). Toward a theory of individual differences and leadership: Understanding the motivation to lead. Journal of Applied Psychology, 86(3), 481-498.

Cochran, W. G. (1977). Sampling Statistics (3 ${ }^{\text {rd }}$ ed.). New York: Wiley and Sons.

Dalton, J. C., \& Sullivan, M. H. (2008). Expanding global horizons. In K. J. Osfield (Ed.), Internationalization of student affairs and services, 7-12. Washington, DC: NASPA.

Duch, B. J., Groh, S. E., \& Allen, D. E. (2001). Why problem-based learning? A case study of institutional change in undergraduate education. In B. J. Duch, S. E. Groh, \& D. E. Allen (Eds.), The power of problem-based learning, 3-11. Sterling, VA: Stylus Publishing, LLC.

Dugan, J. P., \& Komives, S. R. (2007). Developing leadership capacity in college students: Findings from a national study. A report from the Multi-Institutional Study of Leadership. College Park, MD: National Clearinghouse for Leadership Programs.

Earnest, G. W. (2003). Study abroad: A powerful new approach for developing leadership capacities. Journal of Leadership Education, 2(2), 46-56.

Hofstede, G., \& Hofstede, G. J. (2004). Cultures and organizations: Software of the mind (2 $2^{\text {nd }}$ ed.). New York: McGraw Hill.

Institute of International Education (2012). Open doors report on international Educational exchange: Duration of U.S. study abroad. Retrieved from http://www.iie.org/opendoors

Kehl, K., \& Morris, J. (2007). Differences in global-mindedness between short-term and semester-ong study abroad participants at selected private institutions. Frontiers: The Interdisciplinary Journal of Study Abroad, 15, 67-79.

Kuh, G. D. (2008). High-impact educational practices: What they are, who has access to them, and why they matter. Washington, DC: American Association of Colleges and Universities.

Martinez, C. A. (2012). Preparing global leaders: A theoretical model for understanding the development of intercultural competency. Unpublished dissertation. University of San Diego.

Montgomery, J. F., \& Arensdorf, J. (2012). Preparing globally competent leaders through innovative study abroad experiences. Journal of Leadership Studies, 6(1), 64-71. 
Moore, L. L., Boyd, B. L., Rosser, M. H., \& Elbert, C. (2009). Developing an international agricultural leadership program to meet the needs of a global community. Journal of Leadership Education, 8(1), 118-129.

NAFSA (2003). Securing America's future: Global education for a global age. Washington DC: NAFSA: Association of International Educators.

Oddou, G. R., \& Mendenhall, M. E. (2008). Global leadership development. In M. E. Mendenhall, J. S. Osland, A. Bird, G. R. Oddou, \& M. L. Maznevski (Eds.), Global leadership: Research, practice, and development, 160-174. Abingdon, England: Routledge.

Ostick, D. T., \& Wall, V. A. (2011). Considerations for culture and social identity dimensions. In S. R. Komives, J. Dugan, J. E. Owen, C. Slack, \& W. Wagner (Eds.), Handbook for student leadership programs $\left(2^{\text {nd }}\right.$ ed.). San Francisco: Jossey-Bass.

Robinson, B. D. (2005). Bringing “worldmindedness" to students of leadership. Journal of Leadership Education, 4(1), 79-89.

Rosch, D. M., \& Anthony, M. D. (2012). Leadership pedagogy: Putting theory to practice. New Directions for Student Services, 2012 (140), 37-51. doi: 10.1002/ss.20030

Scoffham, S., \& Barnes, J. (2009). Transformational experiences and deep learning: The impact of an intercultural study visit to India on UK initial teacher education students. Journal of Education for Teaching, 35(3), 257-270.

Slavin, R., \& Smith, D. (2009). The relationship between sample sizes and effect sizes in systematic reviews in education. Educational Evaluation and Policy Analysis, 31(4), 500-506. doi: $10.3102 / 0162373709352369$

Wibbeke, E. S. (2009). Global business leadership. Burlington, MA: Butterwork-Heinenmann.

\section{Author Biographies}

Dr. David M. Rosch serves as an Assistant Professor in the Agricultural Education program at the University of Illinois at Urbana-Champaign. His particular areas of interest include student leadership development and the accurate assessment of leadership effectiveness.

Dr. Paige Haber-Curran is an assistant professor in Student Affairs in Higher Education at Texas State University, San Marcos, Texas. 